(C) <2020 $>$. This manuscript version is made available under the CC-BY-NC-ND 4.0 license http://creativecommons.org/licenses/by-nc-nd/4.0/

The definitive publisher version is available online at https://doi.org/

10.1016/i.phrs.2020.105029 


\section{The Need For Physiological Phenotyping To Develop New Drugs For}

\section{Airways Disease}

Chapman, David G1,2; King, Gregory $\mathrm{G}^{1,3,4,6}$; Robinson, Paul $\mathrm{D}^{1,5,6}$, Farah, Claude $\mathrm{S}^{1,6,7}$;

Thamrin, Cindy $y^{1,6}$

${ }^{1}$ Airway Physiology and Imaging Group and Woolcock Emphysema Centre, The Woolcock Institute of Medical Research, The University of Sydney, Glebe NSW 2037, Australia.

${ }^{2}$ School of Life Sciences, Faculty of Science, University of Technology Sydney, Ultimo NSW 2007, Australia.

${ }^{3}$ Department of Respiratory Medicine, Royal North Shore Hospital, St. Leonards NSW 2065, Australia.

${ }^{4}$ NHMRC Centre of Excellence in Severe Asthma, New Lambton Heights NSW 2305, Australia.

${ }^{5}$ Department of Respiratory Medicine, The Children's Hospital at Westmead, Westmead NSW 2145, Australia.

${ }^{6}$ Faculty of Medicine and Health Sciences, The University of Sydney, NSW 2006, Australia

7 Department of Thoracic Medicine, Concord Repatriation General Hospital, Concord NSW 2137, Australia

Corresponding Author: Dr David G Chapman

Address: Airway Physiology and Imaging Group,

Woolcock Institute of Medical Research,

431 Glebe Point Road, Glebe NSW 2037, Australia

Phone: +61294632929

email: david.chapman@woolcock.org.au 


\section{Abstract}

Asthma and COPD make up the majority of obstructive airways diseases (OADs), which affects $\sim 11 \%$ of the population. The main drugs used to treat OADs have not changed in the past five decades, with advancements mainly comprising variations on existing treatments. The recent biologics are beneficial to only specific subsets of patients. Part of this may lie in our inability to adequately characterise the tremendous heterogeneity in every aspect of OAD. The field is currently moving towards the concept of personalised medicine, based on a focus on treatable traits that are objective, measurable and modifiable. We propose extending this concept via the use of emerging clinical tools for comprehensive physiological phenotyping. We describe, based on published data, the evidence for the use of functional imaging, gas washout techniques and oscillometry, as well as potential future applications, to more comprehensively assess and predict treatment response in OADs. In this way, we hope to demonstrate how physiological phenotyping tools will improve the way in which drugs are prescribed, but most importantly, will facilitate development of new drugs for OADs.

\section{Keywords}

oscillometry; Obstructive Airways Disease; phenotyping; inert gas washout; ventilation imaging 


\section{Introduction}

Asthma and COPD make up the majority of obstructive airways diseases (OADs) and airflow obstruction is present in around $11 \%$ of the population(1) (defined by the older criterion of post-bronchodilator FEV1/FVC ratio of 0.70 , prior to the introduction of new criteria(2)). The annual cost of asthma alone to the Australian economy in over 2 million asthmatic sufferers is nearly \$AUD30M. The clinical expression of both asthma and chronic obstructive pulmonary disease (COPD) are highly variable and heterogeneous, as well as the responses to treatment. The histopathology of asthma and COPD also differ markedly, although there is overlap in clinical and pathophysiologic features e.g. alveolar enlargement(3) (4), loss of lung elasticity $(5,6)$, inflammation(7) and bronchodilator responsiveness(8).

Until the recent developments on biological treatments in asthma and COPD, the main drugs used to treat OADs have not changed since the introductions of salbutamol in 1969, the inhaled corticosteroid (ICS) beclomethasone in 1972 (9), and ipratropium in 1974. Better versions have arrived but the 'new treatment paradigms' for OADs are just varying combinations of long acting versions of those three basic drugs, e.g. dual long acting $\beta_{2^{-}}$ agonist (LABA) / long acting muscarinic antagonist (LAMA) vs ICS containing formulations in COPD, and regular vs as needed (PRN) ICS in asthma. The clinical trials to test efficacy of these variations required thousands of subjects to be enrolled in each trial. The large numbers are due to the high degree of heterogeneity in the underlying pathophysiologic processes of the study populations. It is highly unlikely that there will be any further 'development' of those 3 drug classes given that there are once-daily preparations of highly potent formulations, of low systemic activity, delivered to the lungs by highly efficient aerosol delivery devices. The problem remains that we (clinicians and researchers) have not 
defined airways diseases in sufficient depth, to allow development of new drugs to proceed with any confidence; medications with specific targets may work for some but not others (biologics being a case in point), due to the wide heterogeneity in the disease population.

\section{Physiological Phenotyping and Treatable Traits}

OADs are traditionally given disease labels (diagnoses). The Global Initiative for Asthma defines asthma as a heterogeneous disease often associated with chronic airway inflammation in which symptoms and airflow obstruction vary over time(10). The Global Initiative for COPD defines COPD as persistent respiratory symptoms and airflow limitation caused by inhalation of noxious particles/gases(11). It is associated with airway and/or alveolar abnormalities. We note with particular interest that variability in both symptoms and lung function are a key distinguishing feature between asthma and COPD. In practice, diagnosis of OADs are done predominantly by symptoms alone and by response to treatment, both of which perform poorly since neither are sensitive nor specific, and can suffer from poor subjective perception or recall bias. Furthermore, many patients' symptom perception is not in proportion to their underlying disease severity(12). The gold standard measurement of airflow obstruction, spirometry, is infrequently done and abnormal spirometry can occur due to a variety of pathophysiological processes, which also makes it non-specific for OAD diagnosis. Therefore, the definitions by which labels are given are problematic. A common definition of asthma for clinical trials and epidemiological studies is a past doctor diagnosis of asthma and respiratory symptoms in the absence of significant smoking history, with or without bronchodilator reversibility. A common definition of COPD is respiratory symptoms, smoking history and obstructed spirometry, in the absence of any doctor diagnosis of asthma. However, the 'Dutch hypothesis' arose from Orie et al $(13,14)$ in 
which asthma, bronchitis and COPD were considered a continuum of airways disease, rather than being considered as separate entities. Within this paradigm, genetic predisposition (family history and genetic associations), early life exposures (e.g. maternal smoking and infections), airway hyperresponsiveness, allergy, airway narrowing, reversibility in response to treatment, day-to-day variability and inflammatory phenotype, all play a part in the manifestation of disease, regardless of whether it is asthma or COPD. This inherently suggests that OADs should be characterised extensively in a clinical and pathophysiologic sense.

Although this concept is not yet commonplace in clinical practice, there is increasing appreciation in the field for the idea of label-free diagnosis(15), with an emphasis on treatable traits, i.e. those that can be modified by treatment(16), biomarkers and consequently 'precision' or 'tailored' therapy, rather than disease labelling. The ultimate ambition of this approach is the determination of endotypes of OAD, in which specific pathways are identified that control the disease and can be targeted to resolve the clinical manifestations(17). Compare this with other common diseases, such as coronary heart disease, hypertension and diabetes, where despite having different underlying causes and clinical significances in individuals, the focus is instead on treatment on the basis of measurable biomarkers(16). In the same way, we argue that OAD requires a similar approach, rather than just based on disease labels (diagnoses) such as asthma and COPD. While this goal has yet to be realised in respiratory medicine, the discovery of molecular phenotypes and associated inflammatory markers has successfully driven recent drug development such as the new biological treatments $(18,19)$. A recent example is the realisation that blood eosinophilia identifies an asthma phenotype that may respond to anti- 
IL5 targeted treatment. The individual response rate at the outset of such treatment may vary although there is a mean group benefit. Furthermore, the definition of response is debated but often relates to patient reported outcomes rather than an objective marker of the underlying disease being treated.

We propose that physiological phenotyping can take us further, enabling us to better take into account the heterogeneous origins and pathophysiological mechanisms of OADs, and consequently better characterise responses to treatment, in the form of physiologically defined treatable traits. Some of these concepts are already known and already in use in clinical practice to varying extents, e.g. peak flow variability and airway hyperresponsiveness.

\section{Physiological Phenotyping: What Tools are Available?}

The tools that are useful for physiological phenotyping take into account the underlying anatomy and physiology of the lung. The lung is an asymmetrically shaped organ, with an elastic alveolar component supplied by asymmetrically bifurcating airways which have a mechanical compliance that is matched to alveolar compliance. This anatomical structure leads to ventilation being somewhat uneven (ventilation heterogeneity) and with increasing age, ventilation reduces and even ceases in the basal portions of the lung (airway closure), while in non-basal zones, ventilation becomes more heterogeneous. Phenotyping tools ideally also allow us to measure the function of the large and small airways. This is important because spirometry is insensitive to small airway function, yet this is the site where early abnormalities are thought to manifest(20). 
Functional imaging allows measurement of ventilation heterogeneity. Computed

Tomography (CT) is easily accessible and relatively cheap, and its most clinically relevant use is in measuring lung density (emphysema, gas trapping), providing a measure of extent and distribution. Magnetic Resonance Imaging (MRI), Positron Emission Tomography (PET) and Single Photon Emission Computed Tomography (SPECT) are imaging techniques that provide measurements of ventilation distribution. They have been used extensively in research and will likely be used routinely in the clinical assessment of OAD in future, but require further research to achieve this.

Lung function techniques that reflect ventilation heterogeneity include inert gas washout techniques, especially the multiple breath washout (MBW) technique. Recent standardisation work, across both paediatrics and adult testing $(21,22)$, has resulted in validated commercial equipment $(23,24)$, and increased interest in use in clinical care. The technique may utilise an exogenous inert gas (e.g. sulphur hexafluoride (SF6), helium or argon) which is inhaled in low concentration until steady state is reached within the lungs (wash-in). Once the inspired inert gas is removed, the subject then breathes room air to 'wash out' the gas from the lungs and the pattern of the inert gas concentration change during each breath, as the inert gas is progressively washed out of the lungs by normal breathing, provides information on the severity of ventilation heterogeneity (25). An alternative method is to utilise the nitrogen that is resident in the lungs (nitrogen washout test or resident gas technique). A nitrogen $\left(\mathrm{N}_{2}\right)$ inert gas washout test does not require an initial wash-in phase as the gas of interest is already resident within the lungs. During washout $100 \%$ oxygen washes $\mathrm{N}_{2}$ out of the lungs. Since ventilation distribution is determined predominantly at the small airway level, MBW reflect heterogeneity of function 
in the small airway compartment. Advances in technology will provide potentially more clinically useful parameters from this technique(26).

The forced oscillation technique (FOT), also known as oscillometry, is another method, which measures the mechanical properties of the respiratory system (lungs and upper and lower airways), based on the response to oscillatory pressure or flow stimuli, usually applied at the mouth and during quiet, tidal breathing. The response of the respiratory system is measured by the input impedance, i.e. the ratio between pressure and airflow oscillations at the mouth. This in turn can be partitioned into the mechanical parameters resistance (the flow-dependent component of impedance, which primarily reflects airway calibre) and reactance (the volume-dependent component, which primarily reflects elasticity of the respiratory system). Thus, both oscillatory resistance and reactance have a physiologic basis that suggests that they should be physiologically informative in OAD. Oscillations of multiple frequencies can be delivered simultaneously, with typical frequencies used being 5 , 11 and $19 \mathrm{~Hz}$. This is important because different parts of the lung respond to different frequencies - while resistance and reactance at $5 \mathrm{~Hz}$ reflect the mechanical properties of the airway tree, the influence of the small airways and peripheral lung diminish with increasing frequency. The frequency dependence of resistance between 5 to $19 \mathrm{~Hz}$ has been shown to reflect heterogeneity in the distribution of airway narrowing and/or closure across the airway tree(27-29). Furthermore, it is possible to track changes in resistance and reactance within a breathing cycle, which can be useful to non-invasively detect expiratory flow limitation during breathing(30). 
Armed with these tools, physiological phenotypes may not only help us provide better insight into the causal mechanisms of disease, they may also help us assess interventions, e.g. bronchodilator responsiveness measured by FOT and MBW measurements of ventilation heterogeneity could be helpful in identifying patients that respond to bronchodilator or inhaled corticosteroid treatment, or provide more comprehensive markers of response to both existing and new treatments for OAD. Monitoring of disease activity i.e. progression of airflow obstruction, changes in day-to-day variability of airway calibre (that characterises asthma), risk of exacerbations or attacks, early detection of those at risk of disease progression (e.g. rate of loss of FEV1) are just some examples of how physiologic phenotyping, when combined with cellular and genetic markers of disease, can provide the necessary information to advance the understanding and management of OADs.

\section{Current Evidence for Clinical Utility}

Here we describe, based on published data, the evidence for the use of functional imaging, MBW and FOT to better assess and predict treatment response in OADs. In this way, we hope to demonstrate how physiological phenotyping tools will improve the way in which drugs are prescribed, but most importantly, will facilitate development of new drugs for OADs.

\section{Paediatric Utility}

\section{Cystic Fibrosis}

MBW is of particular interest in paediatrics due to its high feasibility as a tidal breathing technique: $>80 \%$ feasibility reported in infancy and preschool age ranges and $>90 \%$ above 
that age range(31). The OAD where MBW is closest to integration into clinical care is Cystic Fibrosis (CF): greater sensitivity to detect early OAD vs spirometry has been shown across all ages(31), with progression over time(32), and exciting ability to detect the beneficial effects of intervention $(33,34)$. These beneficial effects of intervention can be detected in far smaller numbers than required for spirometry $(33,35)$, and its main outcome Lung Clearance Index ( $\mathrm{LCl})$ has been formally endorsed as a primary outcome for research studies(36). This has led to the first successful implementation of $\mathrm{LCl}$ as a primary outcome measure in large pharmaceutical sponsored multicentre international studies(37) using a structured approach to training, certification and quality control of MBW data(38).

\section{Asthma and wheeze}

MBW utility in paediatric asthma is less well defined but emerging(39). Histological changes in early asthma have been demonstrated in endobronchial biopsies in recurrent wheezers during the preschool years (e.g. higher reticular basement membrane thickness and mucosal eosinophilia), and were not only associated with higher ventilation inhomogeneity, but also later early school age recognised markers of asthma (exhaled nitric oxide levels)(40). $\mathrm{LCl}$ is increased in school aged asthmatic subjects, compared to healthy controls(41), is related to $\mathrm{AHR}(42)$ and is higher in those with poor asthma control(43). Increased ventilation inhomogeneity is still detectable in well controlled asthmatics after SABA administration $(44,45)$. Advanced analysis of the change in phase III slope throughout MBW suggests a pattern of abnormality in the conducting airways rather than acinar airway abnormality in paediatric asthma(42-45). 
The utility of oscillometry in paediatric asthma has also been of long standing interest due to its high feasibility as a tidal breathing test in young children(46). Diagnostic utility of conventional FOT methodologies (i.e. mean values of resistance and reactance over a recording period) in children with asthma appear limited $(47,48)$. FOT parameters objectively measure bronchodilator response $(49,50)$ and airways hyperresponsiveness $(51$, 52). However, within-breath differences in FOT parameters appear to hold additional utility to conventional mean measurements across the monitoring period. Czovek and colleagues examined utility in preschool subjects with acute and recurrent wheeze(53). The change between end-inspiratory and end-expiratory resistance detected airway obstruction with high sensitivity and specificity ( $92 \%$ and $89 \%$, respectively) in the acute wheeze setting, and was able to distinguish children with recurrent wheeze from healthy children with high sensitivity.

\section{Adult Utility}

It should be noted that the role of spirometry as a diagnostic test of airway function for OADs in adults is, in itself, bona fide physiological phenotyping. The accuracy and ability to perform spirometry repeatedly meant the test could be used as an important endpoint in multicentre clinical trials to document efficacy of therapeutic targets. Nevertheless, a monolithic view of airway function that can only be assessed by spirometry, has resulted in a respiratory community that has struggled to grapple with the complexity of airway physiology and the heterogeneous nature of OADs. 
This can be appreciated in the approach to COPD where the condition is defined by abnormal spirometry. Yet, clinicians have long appreciated the importance of emphysema observed in some patients that have normal spirometry and another group of patients that seem to have 'early' lung disease or 'at risk' of developing COPD. Here, guidelines have variably introduced (and removed) new categories to define these patient groups such as "Stage 0" in the 2001 GOLD publication that was subsequently removed $(54,55)$.

Large observational cohort studies such as Spiromics and COPDGene have contributed to renewed interest in understanding 'early' COPD, especially in smokers who have preserved FEV1/FVC ratio who may progress towards obstruction. Significant effort has been made to identify molecular signatures to identify these patients but along the way this has led to greater appreciation of abnormalities in imaging and lung function that can also be assessed. Previous work from our group in such 'smokers with normal spirometry' found abnormalities were frequently detected in peripheral airway function whether measured with MBW or oscillometry(56). Interestingly, most patients displayed an abnormality in one but not both peripheral lung function modalities highlighting, yet again, the importance of a multifaceted approach to physiologically phenotyping patients using a variety of tests.

Oscillometry is now an established clinical lung function test with commercial devices increasingly available and the recent publication of a standards document to guide its implementation into a clinical laboratory(57). Just as is the case in paediatrics, it has the appeal of being a relatively effort independent test and, hence, is perfectly suited for monitoring patients with very severe disease or the very old. In a pilot study of people with 
COPD, Milne et al(58) found a correlation between baseline oscillometry and the subsequent improvement in gas trapping following the inhalation of a long acting betaagonist. Indeed, subsequent work confirmed that oscillometry in COPD measures those areas of lung that are participating in ventilation (and hence likely to respond to an inhaled medication) (59). Thus, oscillometry may serve as a useful predictor of specific therapeutic interventions. In contrast, current COPD guidelines are heavily focussed on symptoms, and evaluation of a long acting bronchodilator in an individual patient involves switching or adding another therapeutic class if the symptomatic response is deemed less than optimum.

\section{Asthma}

The importance of small airways disease in asthma is now established. Here, therapeutics have sought to optimise delivery to the periphery of the lung with mixed success (60). The importance of having the correct tools to assess such intervention is once again highlighted. For example, the presence of a bronchodilator response measured with oscillometry identifies more patients with poorly controlled asthma compared to spirometry(61). Meanwhile, MBW indices improve with treatment, both in mild-to-moderate(62) as well as severe uncontrolled asthma(63). In severe eosinophilic asthma, we recently reported on the early improvement in MBW indices after the commencement of anti-IL5 treatment(64). Importantly, improvement in these indices correlates with symptom improvements and may be a predictor of a more sustained symptomatic response. In mild-to-moderate asthma, MBW indices predicted symptomatic response to ICS titration, with greater apparent sensitivity than exhaled nitric oxide (FeNO), whereas FEV1 did not(65). In severe uncontrolled asthma, both MBW and oscillometry predicted improvements with high dose ICS, again where FEV1 did not(63). Both MBW and oscilllometry have been studied 
extensively in asthma but often in smaller single centre studies. The recent publication of the multinational ATLANTIS study is the first to bridge this gap reporting on the role of such tests in assessing the different phenotypes in asthma(66).

In terms of imaging, MRI-based ventilation defect measures relate to asthma symptoms and quality of life, independently to oscillometry(67). More importantly, they are normalised by biologic treatment in asthma(68).

\section{Other diseases and co-morbidities}

In addition to applications in smokers, COPD and asthma, MBW and oscillometry have also been shown to be a sensitive measure of small airway function in bronchiolitis obliterans in haemopoietic stem cell recipients(69), and airway dysfunction in obesity(70). Similarly, ventilation imaging has also provided important insights into the respiratory effects of obesity(71), as well as in detection of early lung disease in cystic fibrosis(72).

\section{Physiological phenotyping: some pitfalls}

If these novel physiological tools are now available, and if the body of recent clinical studies suggest that they have consistent and strong clinical associations, then why has there been little or slow uptake into respiratory medicine practice? Why have we not moved forward from conventional spirometry?

\section{Structure-function relationships in pathology}

A potential reason may be the lack of strong or consistent structure-function correlations with histopathological measures. For example, reticular basement membrane thickness 
does not correlate with ventilation heterogeneity measured by inert gas washout in paediatric patients with asthma or severe wheeze $(40,73)$. In contrast, increased ventilation heterogeneity in patients with CF correlated with reticular basement membrane thickness and HRCT scores of abnormal lung structure $(73,74)$. There is circumstantial evidence that oscillometry is sensitive to airway remodelling in asthma, since the relationship between lung volume and respiratory system conductance (reciprocal of resistance) does not normalise following bronchodilator administration(75). In terms of inflammation, ventilation heterogeneity in diffusion-dependent airways (i.e. acinar airways) correlated with sputum neutrophils whereas heterogeneity in convection-dependent airways (i.e. conducting airways) correlated with sputum eosinophils(76).

The mixed evidence is perhaps not surprising since these tests of lung mechanics and ventilation heterogeneity by their nature measure the summative process of many pathological abnormalities, rather than individual cellular interactions. ASM contraction, airway thickening due to inflammation, as well as structural remodelling of the ASM, subepithelial layer, reticular basement membrane or epithelial layer, can all contribute to an overall increase in airway resistance. Similarly, changes in alveolar size, loss of alveolar septa or changes in surfactant function would all contribute in varying extents to reduced lung compliance. All of these in turn would contribute to changes in ventilation distribution. Given this complexity, it is difficult to directly and specifically infer the pathology underlying some of these physiologic measures.

On the other hand, functional imaging may disentangle the individual contributions of different pathological processes. Recent development of a complex image registration 
technique called Parametric Response Mapping (PRM) allows comparison of lung density on CT between functional residual capacity and total lung capacity in order to distinguish small airways disease from emphysema(77). Importantly, a post-mortem study recently provided much needed pathological verification of PRM, reporting that PRM small airway function corresponded to abnormal terminal bronchial pathology, while PRM emphysema corresponded to alveolar enlargement(78). Ventilation measures from MRI also show similar promise; extent of non-ventilated lung volume correlates with eosinophilic inflammation in sputum and mucus plugs and, may also reflect airway tone(79). Finally, the recent development and validation of optical coherence technology (OCT), which allows quantification of airway wall layers, may provide a sensitive and comparatively non-invasive method to measure multiple lung sites for each individual $(80,81)$. A combination of OCT and ventilation imaging may be able to further link specific structural changes with physiological phenotypes of OAD and thereby promote localised and pathology-guided intervention.

\section{Moving beyond spirometry?}

Despite its own lack of validation in structure-function studies, spirometry has been and will likely remain a cornerstone of respiratory measurement. It has the advantage of being simpler in principle to understand and explain, even though it difficult to perform in some. In contrast, the tests described in this paper are complex in underlying principles and require good knowledge of underlying basic pulmonary physiology and skill in teaching by experts. Whilst the feasibility to train operators across a large number of sites within international research studies with techniques such as these has been demonstrated(82), 
and provides insight into what infrastructure may be required for widespread clinical implementation(38), this has not been done to date. This and the lack of guideline recommendations on how to utilise these tests to improve clinical outcomes are the final hurdles before widespread clinical implementation. Future studies assessing and predicting response to treatment, outcome risks and monitoring, and especially determining magnitude of clinically meaningful changes remain areas of urgently needed research. Also, the most appropriate test choice will likely differ according to clinical scenario. For example, inert gas washout may be sensitive to detect change in subjects with CF or bronchiolitis obliterans syndrome, whereas oscillometry may offer greater insight in asthma or COPD.

\section{Emerging Applications}

\section{Lung volume dependence}

There is growing evidence that physiological measurements that encompass the entire lung volume range may provide clinically meaningful insight into OAD. As described above, imaging methods such as PRM examine changes in lung density over excursions in lung volume to provide insight into small airways disease and emphysema. While PRM has predominantly been measured in COPD, recent evidence that it correlates with asthma control and quality of life suggests it also has clinical utility in asthma (83). Similarly, extending MBW through multiple inspiratory capacity manoeuvres after inert gas concentrations fall below $2 \%$ allows calculation of the volume of trapped gas at functional residual capacity(84). Similarly, the non-linear relationship between lung volume and reactance is thought to indicate the volume at which airway closure begins since it correlates with predicted closing capacity in people without lung disease(85). The reactance 
measured at the onset of airway closure is an independent predictor of asthma control(86), suggesting that it reflects important clinical information not detected by traditional lung function. Since airway closure and gas trapping are well-recognised markers of severe disease, the measurement of early airway closure and gas trapping provides attractive measures for phenotyping OADs.

\section{Home monitoring and day-to-day variability}

The simplicity and ease of oscillometry lends itself to frequent/daily monitoring particularly in the home where unsupervised spirometry or peak flow measurements remain challenging. Technological advances now allows measurements to be sent over (wireless) internet networks increasing its usefulness in telemedicine. Feasibility has been demonstrated in both children under parental supervision(87), adults with asthma(88) and elderly people with $\operatorname{COPD(89).~A~recent~large~trial~suggested~an~improvement~in~re-~}$ hospitalisation rates with home monitoring using oscillometry compared to usual care in COPD patients with a previous exacerbation(90).

Day-to-day variability appears to offer exciting insight into the variable airflow obstruction that characterises asthma. In children, day-to-day variability in resistance or reactance is increased in those with poor asthma control, and missed by peak flow monitoring(91). Home telemonitoring over longer term (months) reveal patterns of increased day-to-day variability prior to an exacerbation in both asthma(87) as well as COPD(92), suggesting utility in detecting onset of exacerbation. 
Furthermore, there is promise in the use of advanced analysis techniques to better capture this day-to-day variability in lung function. Specific patterns in lung function over time have been shown to occur naturally and altered as a result of pathology, as well as in response to stimuli or treatment(93). Day-to-day patterns in peak expiratory flow are different between health and asthma(94), and are altered and predict response to treatment in asthma(95, 96) (97). These patterns also relate to asthma control(98), and could be used to predict future risk of exacerbations(99). Combining these approaches with oscillometry has the potential to further increase sensitivity in predicting exacerbations(100).

As these new methodologies mature, their application to lung function variability could open a new era of research in OAD. First, having an objective marker for detecting exacerbation onset, perhaps earlier than symptoms, may provide novel targets for pharmacological developments, since it is likely that the initial immune response during an exacerbation is significantly different to when symptoms are present. Second, the ability to predict exacerbations in a more timely manner (e.g. days or weeks versus the current best predictor of a previous exacerbation in the past 12 months) may provide the opportunity to develop medications with differing timing/dynamics of action, perhaps instigating a change in the way we currently treat exacerbations.

\section{Complex system approaches}

While these physiological tools offer superior objectivity and sensitivity to symptoms and conventional lung function, separately they still represent only specific aspects of a larger, more complex picture. The lung in health and disease comprises an essentially complex 
system, which may not be captured by single, simple biomarkers. A complex system has multiple components all interacting with one another, and exhibits nonlinearities in structure and function, often resulting in deterministic patterns in measureable markers over time $(93,101)$. Thus, truly comprehensive disease phenotyping should take these complex behaviours into account, and include physiological as well as genetic, molecular and cellular measures, in addition to patient-based measures such as obesity, adherence, symptom perception, etc (Figure 1). Meanwhile, physiological treatable traits themselves could be visualised as the numerous spokes on a hypothetical wheel (Figure 2). Physiological phenotypes of airways disease could then be described based on the different extents of abnormality along the different spokes, including different variability over time (indicated by the dotted profile). Treatment targeting each physiological trait (or clusters/networks of traits) then aims to reduce these abnormalities to a physiological profile that is more similar to health. In this way physiological phenotyping would contribute to a label-free, treatable traits, approach to the management of OADs.

\section{Conclusions}

Patient-reported outcomes are important diagnosis tools and endpoints in chronic disease such as OADs, and some may argue that research into drug development should focus entirely on symptoms as the endpoint of interest. However, they are by nature subjective, and the physiological processes that contribute to symptoms can be varied. A purely symptom-based approach would be detrimental to future therapeutic developments and eventually patient care will suffer. We are now already moving towards the concept of personalised medicine, based on a focus on treatable traits that are objective, measurable and modifiable. We propose extending this concept via the use of emerging clinical tools for 
measuring lung structure and function, to identify physiological phenotypes and their ability to assess and predict response to treatment. Characterising the physiological characteristics of OAD is clinically useful and will facilitate drug development for OAD, and enable us to account for the tremendous heterogeneity seen in OADs. Furthermore, advances can only be achieved if the complexity of the disease (and patient) is assessed across a number of platforms including lung function, imaging, biomarkers and genetic information where available. This comprehensive approach will enable us to better tailor interventions to the patients that will benefit the most from specific therapeutics.

\section{Conflict of Interest}

D.G. Chapman reports no relevant conflict of interest.

G.G. King reports a collaborative research agreement and IP agreement with Restech, a commercial company producing oscillometry devices. He also reports grants and personal fees for lectures from AstraZeneca, Boehringer Ingelheim, GlaxoSmithKline, Menarini, MundiPharma and Cyclomedica, grants from NH\&MRC, Philanthropic Societies, Sydney University, outside the submitted work.

P.D. Robinson reports research collaborative agreements with manufacturers of oscillometry equipment (Thorasys Ltd), but does not have any financial relationships with that company. His institution, The Children's Hospital at Westmead, have received renumeration for services provided for Multiple Breath Washout training and quality control for pharmaceutical-sponsored and investigator led research studies.

C.S. Farah reports no relevant conflict of interests. He has received personal fees from AstraZeneca, Boehringer Ingelheim, GlaxoSmithKline and Sanofi Genzyme outside the submitted work.

C. Thamrin has a patent WO 2006130922 A1 issued which is broadly relevant to the work, and has intellectual property arrangements with Thorasys Medical Systems and Restech srl, both commercial produces of oscillometry devices, relating to research collaborations, but does not have any financial relationships with either company. 


\section{References}

1. Buist AS, McBurnie MA, Vollmer WM, Gillespie S, Burney P, Mannino DM, Menezes AM, Sullivan SD, Lee TA, Weiss KB, Jensen RL, Marks GB, Gulsvik A, NizankowskaMogilnicka E, Group BCR. International variation in the prevalence of COPD (the BOLD Study): a population-based prevalence study. Lancet. 2007;370(9589):741-750.

2. Quanjer PH, Stanojevic S. Do the Global Lung Function Initiative 2012 equations fit my population? Eur Respir J. 2016;48(6):1782-1785.

3. Biernacki W, Redpath AT, Best JJ, MacNee W. Measurement of CT lung density in patients with chronic asthma. Eur Respir J. 1997;10(11):2455-2459.

4. Mitsunobu F, Mifune T, Ashida K, Hosaki Y, Tsugeno H, Okamoto M, Harada S, Tanizaki Y. Low-attenuation areas of the lungs on high-resolution computed tomography in asthma. J Asthma. 2001;38(5):413-422.

5. Gelb AF, Zamel N. Unsuspected pseudophysiologic emphysema in chronic persistent asthma. Am J Respir Crit Care Med. 2000;162(5):1778-1782.

6. Tonga KO, Chapman DG, Farah CS, Oliver BG, Zimmermann SC, Milne S, Sanai F, Jetmalani K, Berend N, Thamrin C, King GG. Reduced lung elastic recoil and fixed airflow obstruction in asthma. Respirology. 2019.

7. Simpson JL, Scott R, Boyle MJ, Gibson PG. Inflammatory subtypes in asthma: assessment and identification using induced sputum. Respirology. 2006;11(1):54-61.

8. Calverley PM, Burge PS, Spencer S, Anderson JA, Jones PW. Bronchodilator reversibility testing in chronic obstructive pulmonary disease. Thorax. 2003;58(8):659-664.

9. Brown HM, Storey G, George WH. Beclomethasone dipropionate: a new steroid aerosol for the treatment of allergic asthma. Br Med J. 1972;1(5800):585-590.

10. Global Initiative for Asthma. Global Strategy for Asthma Management and Prevention, 2020. Available from www.ginasthma.org. In.

11. Global Initiative for Chronic Obstructive Pulmonary Disease. Global Strategy for the Diagnosis, Management, and Prevention of COPD (2020). In.

12. O'Loghlen SB, Levesque L, Fisher T, DeWit $Y$, Whitehead M, To T, Lougheed MD. Health Services Utilization is Increased in Poor Perceivers of Bronchoconstriction and Hyperinflation in Asthma. The journal of allergy and clinical immunology In practice. 2020.

13. Orie NG. Correlations of emphysema and asthmatic constitution. Acta allergologica. 1961;16:407-409.

14. Postma DS, Boezen HM. Rationale for the Dutch hypothesis. Allergy and airway hyperresponsiveness as genetic factors and their interaction with environment in the development of asthma and COPD. Chest. 2004;126(2 Suppl):96S-104S; discussion 159S-161S.

15. Pavord ID, Beasley R, Agusti A, Anderson GP, Bel E, Brusselle G, Cullinan P, Custovic A, Ducharme FM, Fahy JV, Frey U, Gibson P, Heaney LG, Holt PG, Humbert M, Lloyd CM, Marks G, Martinez FD, Sly PD, von Mutius E, Wenzel S, Zar HJ, Bush A. After asthma: redefining airways diseases. Lancet. 2018;391(10118):350-400.

16. Agusti A, Bel E, Thomas M, Vogelmeier C, Brusselle G, Holgate $S$, Humbert $M$, Jones P, Gibson PG, Vestbo J, Beasley R, Pavord ID. Treatable traits: toward precision medicine of chronic airway diseases. Eur Respir J. 2016;47(2):410-419. 
17. Ray A, Camiolo M, Fitzpatrick A, Gauthier M, Wenzel SE. Are We Meeting the Promise of Endotypes and Precision Medicine in Asthma? Physiological reviews. 2020;100(3):983-1017.

18. Yousuf A, Ibrahim W, Greening NJ, Brightling CE. T2 Biologics for Chronic Obstructive Pulmonary Disease. The journal of allergy and clinical immunology In practice. 2019;7(5):1405-1416.

19. Coverstone AM, Seibold MA, Peters MC. Diagnosis and Management of T2-High Asthma. The journal of allergy and clinical immunology In practice. 2020;8(2):442450.

20. McDonough JE, Yuan R, Suzuki M, Seyednejad N, Elliott WM, Sanchez PG, Wright AC, Gefter WB, Litzky L, Coxson HO, Paré PD, Sin DD, Pierce RA, Woods JC, McWilliams AM, Mayo JR, Lam SC, Cooper JD, Hogg JC. Small-airway obstruction and emphysema in chronic obstructive pulmonary disease. N Engl J Med. 2011;365(17):1567-1575.

21. Robinson PD, Latzin P, Ramsey KA, Stanojevic S, Aurora P, Davis SD, Gappa M, Hall GL, Horsley A, Jensen R, Lum S, Milla C, Nielsen KG, Pittman JE, Rosenfeld M, Singer F, Subbarao P, Gustafsson PM, Ratjen F, Pediatrics ATSAo. Preschool Multiple-Breath Washout Testing. An Official American Thoracic Society Technical Statement. Am J Respir Crit Care Med. 2018;197(5):e1-e19.

22. Robinson PD, Latzin P, Verbanck S, Hall GL, Horsley A, Gappa M, Thamrin C, Arets HGM, Aurora P, Fuchs SI, King GG, Lum S, Macleod K, Paiva M, Pillow JJ, Ranganathan S, Ratjen F, Singer F, Sonnappa S, Stocks J, Subbarao P, Thompson BR, Gustafsson PM. Consensus statement for inert gas washout measurement using multiple- and single- breath tests. Eur Respir J. 2013;41(3):507-522.

23. Singer F, Houltz B, Latzin P, Robinson P, Gustafsson P. A realistic validation study of a new nitrogen multiple-breath washout system. PLoS One. 2012;7(4):e36083-e36083.

24. Tonga KO, Robinson PD, Farah CS, King GG, Thamrin C. In vitro and in vivo functional residual capacity comparisons between multiple-breath nitrogen washout devices. ERJ Open Res. 2017;3(4):00011-02017.

25. Robinson PD, Goldman MD, Gustafsson PM. Inert gas washout: theoretical background and clinical utility in respiratory disease. Respiration. 2009;78(3):339355.

26. Mountain JE, Santer P, O'Neill DP, Smith NMJ, Ciaffoni L, Couper JH, Ritchie GAD, Hancock G, Whiteley JP, Robbins PA. Potential for noninvasive assessment of lung inhomogeneity using highly precise, highly time-resolved measurements of gas exchange. J Appl Physiol (1985). 2018;124(3):615-631.

27. Foy BH, Kay D. A computational comparison of the multiple-breath washout and forced oscillation technique as markers of bronchoconstriction. Respir Physiol Neurobiol. 2017;240:61-69.

28. Foy BH, Soares M, Bordas R, Richardson M, Bell A, Singapuri A, Hargadon B, Brightling C, Burrowes K, Kay D, Owers-Bradley J, Siddiqui S. Lung Computational Models and the Role of the Small Airways in Asthma. Am J Respir Crit Care Med. 2019;200(8):982-991.

29. Lutchen KR, Gillis H. Relationship between heterogeneous changes in airway morphometry and lung resistance and elastance. J Appl Physiol (1985).

1997;83(4):1192-1201. 
30. Dellaca RL, Santus P, Aliverti A, Stevenson N, Centanni S, Macklem PT, Pedotti A, Calverley PM. Detection of expiratory flow limitation in COPD using the forced oscillation technique. Eur Respir J. 2004;23(2):232-240.

31. Robinson PD, Latzin P, Gustafsson P. Multiple-breath washout. In: Frey UMPJFM, editor. European Monograph 47: Paediatric Lung Function: European Respiratory Society Journals Ltd; 2010. p. 87-104.

32. Stanojevic S, Davis SD, Retsch-Bogart G, Webster H, Davis M, Johnson RC, Jensen R, Pizarro ME, Kane M, Clem CC, Schornick L, Subbarao P, Ratjen FA. Progression of Lung Disease in Preschool Patients with Cystic Fibrosis. Am J Respir Crit Care Med. 2017;195(9):1216-1225.

33. Amin R, Subbarao P, Jabar A, Balkovec S, Jensen R, Kerrigan S, Gustafsson P, Ratjen F. Hypertonic saline improves the $\mathrm{LCl}$ in paediatric patients with $\mathrm{CF}$ with normal lung function. Thorax. 2010;65(5):379-383.

34. Amin R, Subbarao P, Lou W, Jabar A, Balkovec S, Jensen R, Kerrigan S, Gustafsson P, Ratjen $\mathrm{F}$. The effect of dornase alfa on ventilation inhomogeneity in patients with cystic fibrosis. Eur Respir J. 2011;37(4):806-812.

35. Aurora P. Multiple-breath inert gas washout test and early cystic fibrosis lung disease. Thorax. 2010;65(5):373-374.

36. Kent L, Reix $P$, Innes JA, Zielen $S$, Le Bourgeois $M$, Braggion $C$, Lever $S$, Arets HGM, Brownlee K, Bradley JM, Bayfield K, O'Neill K, Savi D, Bilton D, Lindblad A, Davies JC, Sermet I, De Boeck K, European Cystic Fibrosis Society Clinical Trial Network Standardisation C. Lung clearance index: evidence for use in clinical trials in cystic fibrosis. J Cyst Fibros. 2014;13(2):123-138.

37. Ratjen F, Hug C, Marigowda G, Tian S, Huang X, Stanojevic S, Milla CE, Robinson PD, Waltz D, Davies JC, group VXi. Efficacy and safety of lumacaftor and ivacaftor in patients aged 6-11 years with cystic fibrosis homozygous for F508del-CFTR: a randomised, placebo-controlled phase 3 trial. Lancet Respir Med. 2017;5(7):557-567.

38. Saunders C, Jensen R, Robinson PD, Stanojevic S, Klingel M, Short C, Davies JC, Ratjen F. Integrating the multiple breath washout test into international multicentre trials. J Cyst Fibros. 2019:S1569-1993(1519)30968-30963.

39. Nuttall AGL, Velásquez W, Beardsmore CS, Gaillard EA. Lung clearance index: assessment and utility in children with asthma. Eur Respir Rev. 2019;28(154):190046.

40. Sonnappa S, Bastardo CM, Saglani S, Bush A, Aurora P. Relationship between past airway pathology and current lung function in preschool wheezers. Eur Respir J. 2011;38(6):1431-1436.

41. Gustafsson PM. Peripheral airway involvement in CF and asthma compared by inert gas washout. Pediatr Pulmonol. 2007;42(2):168-176.

42. Steinbacher M, Pfleger A, Schwantzer G, Jauk S, Weinhandl E, Eber E. Small airway function before and after cold dry air challenge in pediatric asthma patients during remission. Pediatr Pulmonol. 2017;52(7):873-879.

43. Keen C, Olin A-C, Wennergren G, Gustafsson P. Small airway function, exhaled NO and airway hyper-responsiveness in paediatric asthma. Respir Med. 2011;105(10):1476-1484.

44. Macleod KA, Horsley AR, Bell NJ, Greening AP, Innes JA, Cunningham S. Ventilation heterogeneity in children with well controlled asthma with normal spirometry indicates residual airways disease. Thorax. 2009;64(1):33-37. 
45. Zwitserloot A, Fuchs SI, Müller C, Bisdorf K, Gappa M. Clinical application of inert gas Multiple Breath Washout in children and adolescents with asthma. Respir Med. 2014;108(9):1254-1259.

46. Frey U. Forced oscillation technique in infants and young children. Paediatr Respir Rev. 2005;6(4):246-254.

47. Cuijpers CE, Wesseling GJ, Kessels AG, Swaen GM, Mertens PL, de Kok ME, Broer J, Sturmans F, Wouters EF. Low diagnostic value of respiratory impedance measurements in children. Eur Respir J. 1997;10(1):88-93.

48. Lebecque $P$, Stănescu D. Respiratory resistance by the forced oscillation technique in asthmatic children and cystic fibrosis patients. Eur Respir J. 1997;10(4):891-895.

49. Nguyen YT, Demoulin B, Schweitzer C, Bonabel-Chone C, Marchal F. Identification of bronchodilator responsiveness by forced oscillation admittance in children. Pediatr Res. 2007;62(3):348-352.

50. Thamrin C, Gangell CL, Udomittipong K, Kusel MMH, Patterson H, Fukushima T, Schultz A, Hall GL, Stick SM, Sly PD. Assessment of bronchodilator responsiveness in preschool children using forced oscillations. Thorax. 2007;62(9):814-819.

51. Duiverman EJ, Neijens HJ, Affourtit M, de Jongste JC, Kerrebijn KF. Bronchial hyperreactivity measurements by the forced oscillation technique. Eur J Respir Dis Suppl. 1983;128 (Pt 2):415-416.

52. Hall GL, Gangell C, Fukushima T, Horak F, Patterson H, Stick SM, Sly PD, Franklin PJ. Application of a shortened inhaled adenosine-5'-monophosphate challenge in young children using the forced oscillation technique. Chest. 2009;136(1):184-189.

53. Czövek D, Shackleton C, Hantos Z, Taylor K, Kumar A, Chacko A, Ware RS, Makan G, Radics B, Gingl Z, Sly PD. Tidal changes in respiratory resistance are sensitive indicators of airway obstruction in children. Thorax. 2016;71(10):907-915.

54. Pauwels RA, Buist AS, Calverley PM, Jenkins CR, Hurd SS, Committee GS. Global strategy for the diagnosis, management, and prevention of chronic obstructive pulmonary disease. NHLBI/WHO Global Initiative for Chronic Obstructive Lung Disease (GOLD) Workshop summary. Am J Respir Crit Care Med. 2001;163(5):12561276.

55. Singh D, Agusti A, Anzueto A, Barnes PJ, Bourbeau J, Celli BR, Criner GJ, Frith P, Halpin DMG, Han M, Lopez Varela MV, Martinez F, Montes de Oca M, Papi A, Pavord ID, Roche N, Sin DD, Stockley R, Vestbo J, Wedzicha JA, Vogelmeier C. Global Strategy for the Diagnosis, Management, and Prevention of Chronic Obstructive Lung Disease: the GOLD science committee report 2019. Eur Respir J. 2019;53(5).

56. Jetmalani K, Thamrin C, Farah CS, Bertolin A, Chapman DG, Berend N, Salome CM, King GG. Peripheral airway dysfunction and relationship with symptoms in smokers with preserved spirometry. Respirology. 2018;23(5):512-518.

57. King GG, Bates J, Berger KI, Calverley P, de Melo PL, Dellaca RL, Farre R, Hall GL, Ioan I, Irvin CG, Kaczka DW, Kaminsky DA, Kurosawa H, Lombardi E, Maksym GN, Marchal F, Oppenheimer BW, Simpson SJ, Thamrin C, van den Berge M, Oostveen E. Technical Standards for Respiratory Oscillometry. Eur Respir J. 2019.

58. Milne S, Hammans C, Watson S, Farah CS, Thamrin C, King GG. Bronchodilator Responses in Respiratory Impedance, Hyperinflation and Gas Trapping in COPD. COPD. 2018;15(4):341-349. 
59. Milne S, Jetmalani K, Chapman DG, Duncan JM, Farah CS, Thamrin C, King GG. Respiratory system reactance reflects communicating lung volume in chronic obstructive pulmonary disease. J Appl Physiol (1985). 2019;126(5):1223-1231.

60. El Baou C, Di Santostefano RL, Alfonso-Cristancho R, Suarez EA, Stempel D, Everard $M L$, Barnes N. Effect of inhaled corticosteroid particle size on asthma efficacy and safety outcomes: a systematic literature review and meta-analysis. BMC Pulm Med. 2017;17(1):31-31.

61. Cottee AM, Seccombe LM, Thamrin C, King GG, Peters MJ, Farah CS. Bronchodilator response assessed using the forced oscillation technique identifies poor asthma control with greater sensitivity than spirometry. Chest. 2020.

62. Farah CS, King GG, Brown NJ, Downie SR, Kermode JA, Hardaker KM, Peters MJ, Berend N, Salome CM. The role of the small airways in the clinical expression of asthma in adults. J Allergy Clin Immunol. 2012;129(2):381-387, 387 e381.

63. Tang FSM, Rutting S, Farrow CE, Tonga KO, Watts J, Dame-Carrol JR, Bertolin A, King GG, Thamrin C, Chapman DG. Ventilation heterogeneity and oscillometry predict asthma control improvement following step-up inhaled therapy in uncontrolled asthma. Respirology. 2020:10.1111/resp.13772.

64. Farah CS, Badal T, Reed N, Rogers PG, King GG, Thamrin C, Peters MJ, Seccombe LM. Mepolizumab improves small airway function in severe eosinophilic asthma. Respir Med. 2019;148:49-53.

65. Farah CS, King GG, Brown NJ, Peters MJ, Berend N, Salome CM. Ventilation heterogeneity predicts asthma control in adults following inhaled corticosteroid dose titration. J Allergy Clin Immunol. 2012;130(1):61-68.

66. Postma DS, Brightling C, Baldi S, Van den Berge M, Fabbri LM, Gagnatelli A, Papi A, Van der Molen T, Rabe KF, Siddiqui S, Singh D, Nicolini G, Kraft M, group As. Exploring the relevance and extent of small airways dysfunction in asthma (ATLANTIS): baseline data from a prospective cohort study. Lancet Respir Med. 2019;7(5):402-416.

67. Young HM, Guo F, Eddy RL, Maksym G, Parraga G. Oscillometry and pulmonary MRI measurements of ventilation heterogeneity in obstructive lung disease: relationship to quality of life and disease control. J Appl Physiol (1985). 2018;125(1):73-85.

68. Svenningsen S, Haider EA, Eddy RL, Parraga G, Nair P. Normalisation of MRI ventilation heterogeneity in severe asthma by dupilumab. Thorax. 2019;74(11):10871088.

69. Lahzami S, Schoeffel RE, Pechey V, Reid C, Greenwood M, Salome CM, Berend N, King GG. Small airways function declines after allogeneic haematopoietic stem cell transplantation. Eur Respir J. 2011;38(5):1180-1188.

70. Mahadev S, Farah CS, King GG, Salome CM. Obesity, expiratory flow limitation and asthma symptoms. Pulm Pharmacol Ther. 2013;26(4):438-443.

71. Rutting S, Mahadev S, Tonga KO, Bailey DL, Dame Carroll JR, Farrow CE, Thamrin C, Chapman DG, King GG. Obesity alters the topographical distribution of ventilation and the regional response to bronchoconstriction. J Appl Physiol (1985).

2020;128(1):168-177.

72. Marshall H, Horsley A, Taylor CJ, Smith L, Hughes D, Horn FC, Swift AJ, Parra-Robles J, Hughes PJ, Norquay G, Stewart NJ, Collier GJ, Teare D, Cunningham S, Aldag I, Wild JM. Detection of early subclinical lung disease in children with cystic fibrosis by lung ventilation imaging with hyperpolarised gas MRI. Thorax. 2017;72(8):760-762. 
73. Koucký V, Uhlík J, Hoňková L, Koucký M, Doušová $T$, Pohunek P. Ventilation Inhomogeneity and Bronchial Basement Membrane Changes in Chronic Neutrophilic Airway Inflammation. Chest. 2020;157(4):779-789.

74. Gustafsson PM, De Jong PA, Tiddens HA, Lindblad A. Multiple-breath inert gas washout and spirometry versus structural lung disease in cystic fibrosis. Thorax. 2008;63(2):129-134.

75. Brown NJ, Salome CM, Berend N, Thorpe CW, King GG. Airway distensibility in adults with asthma and healthy adults, measured by forced oscillation technique. Am J Respir Crit Care Med. 2007;176(2):129-137.

76. Farah CS, Keulers LA, Hardaker KM, Peters MJ, Berend N, Postma DS, Salome CM, King GG. Association between peripheral airway function and neutrophilic inflammation in asthma. Respirology. 2015;20(6):975-981.

77. Galbán CJ, Han MK, Boes JL, Chughtai KA, Meyer CR, Johnson TD, Galbán S, Rehemtulla A, Kazerooni EA, Martinez FJ, Ross BD. Computed tomography-based biomarker provides unique signature for diagnosis of COPD phenotypes and disease progression. Nat Med. 2012;18(11):1711-1715.

78. Vasilescu DM, Martinez FJ, Marchetti N, Galbán CJ, Hatt C, Meldrum CA, Dass C, Tanabe N, Reddy RM, Lagstein A, Ross BD, Labaki WW, Murray S, Meng X, Curtis JL, Hackett TL, Kazerooni EA, Criner GJ, Hogg JC, Han MK. Noninvasive Imaging Biomarker Identifies Small Airway Damage in Severe Chronic Obstructive Pulmonary Disease. Am J Respir Crit Care Med. 2019;200(5):575-581.

79. Svenningsen S, Haider E, Boylan C, Mukherjee M, Eddy RL, Capaldi DPI, Parraga G, Nair P. CT and Functional MRI to Evaluate Airway Mucus in Severe Asthma. Chest. 2019;155(6):1178-1189.

80. Carpaij OA, Goorsenberg AWM, d'Hooghe JNS, de Bruin DM, van den Elzen RM, Nawijn MC, Annema JT, van den Berge M, Bonta PI, Burgess JK. Optical Coherence Tomography Intensity Correlates with Extracellular Matrix Components in the Airway Wall. Am J Respir Crit Care Med. 2020.

81. d'Hooghe JNS, Goorsenberg AWM, de Bruin DM, Roelofs J, Annema JT, Bonta PI. Optical coherence tomography for identification and quantification of human airway wall layers. PLoS One. 2017;12(10):e0184145.

82. Ratjen F, Hug C, Marigowda G, Tian S, Huang X, Stanojevic S, Milla CE, Robinson PD, Waltz D, Davies JC. Efficacy and safety of lumacaftor and ivacaftor in patients aged 611 years with cystic fibrosis homozygous for F508del-CFTR: a randomised, placebocontrolled phase 3 trial. Lancet Respir Med. 2017;5(7):557-567.

83. Bell AJ, Foy BH, Richardson $M$, Singapuri A, Mirkes $E$, van den Berge $M$, Kay $D$, Brightling C, Gorban AN, Galbán CJ, Siddiqui S. Functional CT imaging for identification of the spatial determinants of small-airways disease in adults with asthma. J Allergy Clin Immunol. 2019;144(1):83-93.

84. King GG, Downie SR, Verbanck S, Thorpe CW, Berend N, Salome CM, Thompson B. Effects of methacholine on small airway function measured by forced oscillation technique and multiple breath nitrogen washout in normal subjects. Respir Physiol Neurobiol. 2005;148(1-2):165-177.

85. Nilsen K, Thien F, Thamrin C, Ellis MJ, Prisk GK, King GG, Thompson BR. Early onset of airway derecruitment assessed using the forced oscillation technique in subjects with asthma. J Appl Physiol (1985). 2019;126(5):1399-1408. 
86. Kelly VJ, Sands SA, Harris RS, Venegas JG, Brown NJ, Stuart-Andrews CR, King GG, Thompson BR. Respiratory system reactance is an independent determinant of asthma control. J Appl Physiol (1985). 2013;115(9):1360-1369.

87. Wong A, Hardaker K, Field P, Huvanandana J, King GG, Reddel H, Selvadurai H, Thamrin C, Robinson PD. Home-based Forced Oscillation Technique Day-to-Day Variability in Pediatric Asthma. Am J Respir Crit Care Med. 2019;199(9):1156-1160.

88. Gulotta C, Suki B, Brusasco V, Pellegrino R, Gobbi A, Pedotti A, Dellaca RL. Monitoring the temporal changes of respiratory resistance: a novel test for the management of asthma. Am J Respir Crit Care Med. 2012;185(12):1330-1331.

89. Timmins SC, Diba C, Thamrin C, Berend N, Salome CM, King GG. The feasibility of home monitoring of impedance with the forced oscillation technique in chronic obstructive pulmonary disease subjects. Physiol Meas. 2013;34(1):67-81.

90. Walker PP, Pompilio PP, Zanaboni P, Bergmo TS, Prikk K, Malinovschi A, Montserrat JM, Middlemass J, Šonc S, Munaro G, Marušič D, Sepper R, Rosso R, Siriwardena AN, Janson C, Farré R, Calverley PMA, Dellaca RL. Telemonitoring in Chronic Obstructive Pulmonary Disease (CHROMED). A Randomized Clinical Trial. Am J Respir Crit Care Med. 2018;198(5):620-628.

91. Robinson PD, Brown NJ, Turner M, Van Asperen P, Selvadurai H, King GG. Increased day-to-day variability of forced oscillatory resistance in poorly controlled or persistent pediatric asthma. Chest. 2014;146(4):974-981.

92. Zimmermann SC, Huvanandana J, Nguyen CD, Bertolin A, Watts JC, Gobbi A, Farah CS, Peters MJ, Dellacà RL, King GG, Thamrin C. Day-to-day variability of forced oscillatory mechanics for early detection of acute exacerbations in COPD. Eur Respir J. 2020.

93. Thamrin C, Frey U, Kaminsky DA, Reddel HK, Seely AJ, Suki B, Sterk PJ. Systems Biology and Clinical Practice in Respiratory Medicine. The Twain Shall Meet. Am J Respir Crit Care Med. 2016;194(9):1053-1061.

94. Gobbi A, Gulotta C, Suki B, Mellano E, Pellegrino R, Brusasco V, Dellacà RL. Monitoring of respiratory resistance in the diagnosis of mild intermittent asthma. Clinical and experimental allergy : journal of the British Society for Allergy and Clinical Immunology. 2019;49(6):921-923.

95. Frey U, Brodbeck T, Majumdar A, Taylor DR, Town GI, Silverman M, Suki B. Risk of severe asthma episodes predicted from fluctuation analysis of airway function. Nature. 2005;438(7068):667-670.

96. Thamrin C, Stern G, Strippoli MP, Kuehni CE, Suki B, Taylor DR, Frey U. Fluctuation analysis of lung function as a predictor of long-term response to beta2-agonists. Eur Respir J. 2009;33(3):486-493.

97. Thamrin C, Taylor DR, Jones SL, Suki B, Frey U. Variability of lung function predicts loss of asthma control following withdrawal of inhaled corticosteroid treatment. Thorax. 2010;65(5):403-408.

98. Thamrin C, Nydegger R, Stern G, Chanez P, Wenzel SE, Watt RA, FitzPatrick S, Taylor $D R$, Frey U. Associations between fluctuations in lung function and asthma control in two populations with differing asthma severity. Thorax. 2011;66(12):1036-1042.

99. Thamrin C, Zindel J, Nydegger R, Reddel HK, Chanez P, Wenzel SE, FitzPatrick S, Watt RA, Suki B, Frey U. Predicting future risk of asthma exacerbations using individual conditional probabilities. J Allergy Clin Immunol. 2011;127(6):1494-1502.e1493. 
100. Gobbi A, Dellacá RL, King G, Thamrin C. Toward Predicting Individual Risk in Asthma Using Daily Home Monitoring of Resistance. Am J Respir Crit Care Med. 2017;195(2):265-267.

101. Frey U, Suki B. Complexity of chronic asthma and chronic obstructive pulmonary disease: implications for risk assessment, and disease progression and control. Lancet (London, England). 2008;372(9643):1088-1099. 
FIGURES

Figure 1. Comprehensive phenotyping of airways disease should take into account

physiological as well as genetic, molecular and cellular measures, in addition to patient-

based measures such as obesity, adherence, symptom perception, etc.

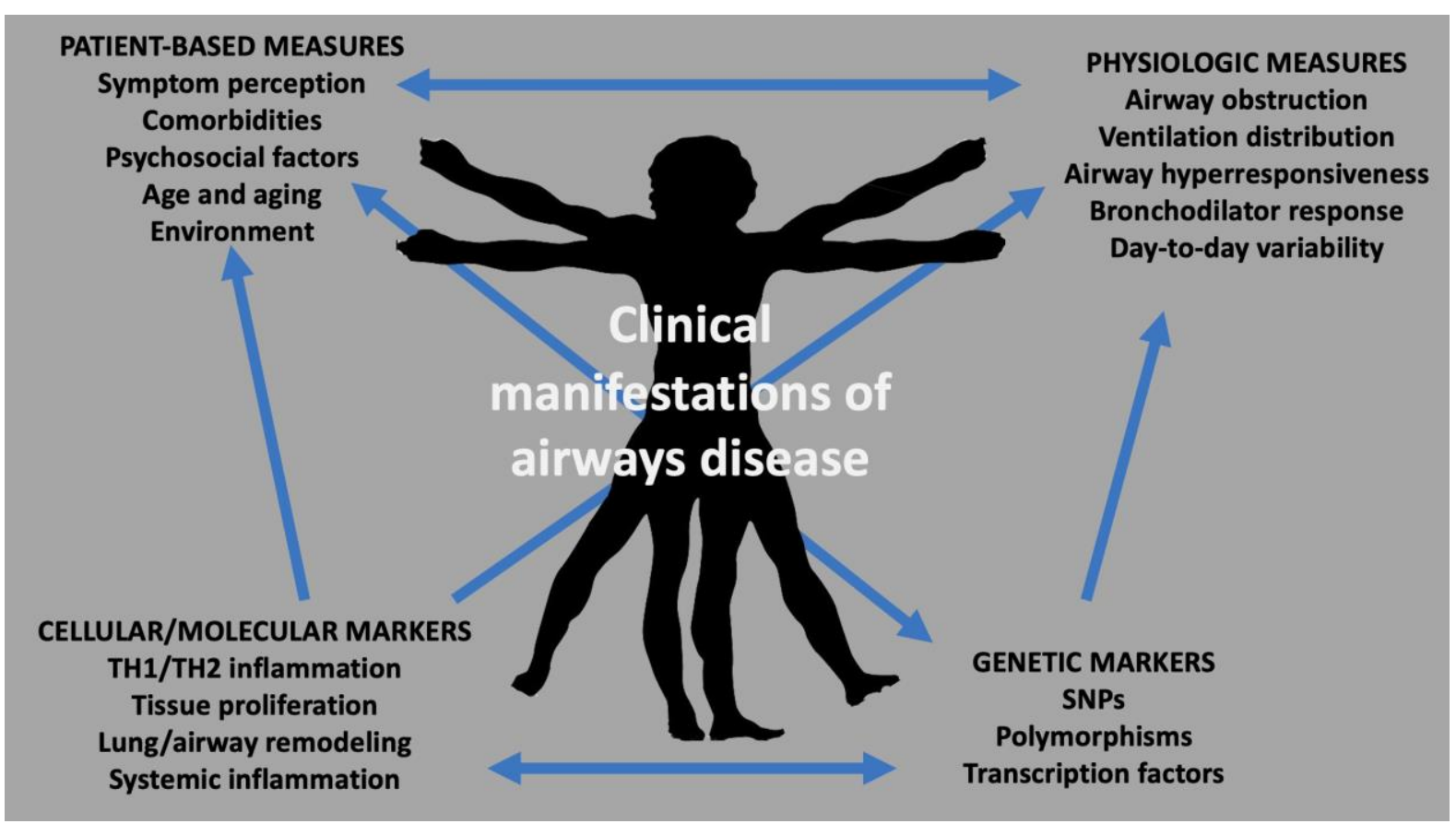


Figure 2. Possible physiological treatable traits. Different airways disease phenotypes can manifest as different profiles, with different extents of abnormality along the different spokes, including different variability over time (indicated by the dotted profile).

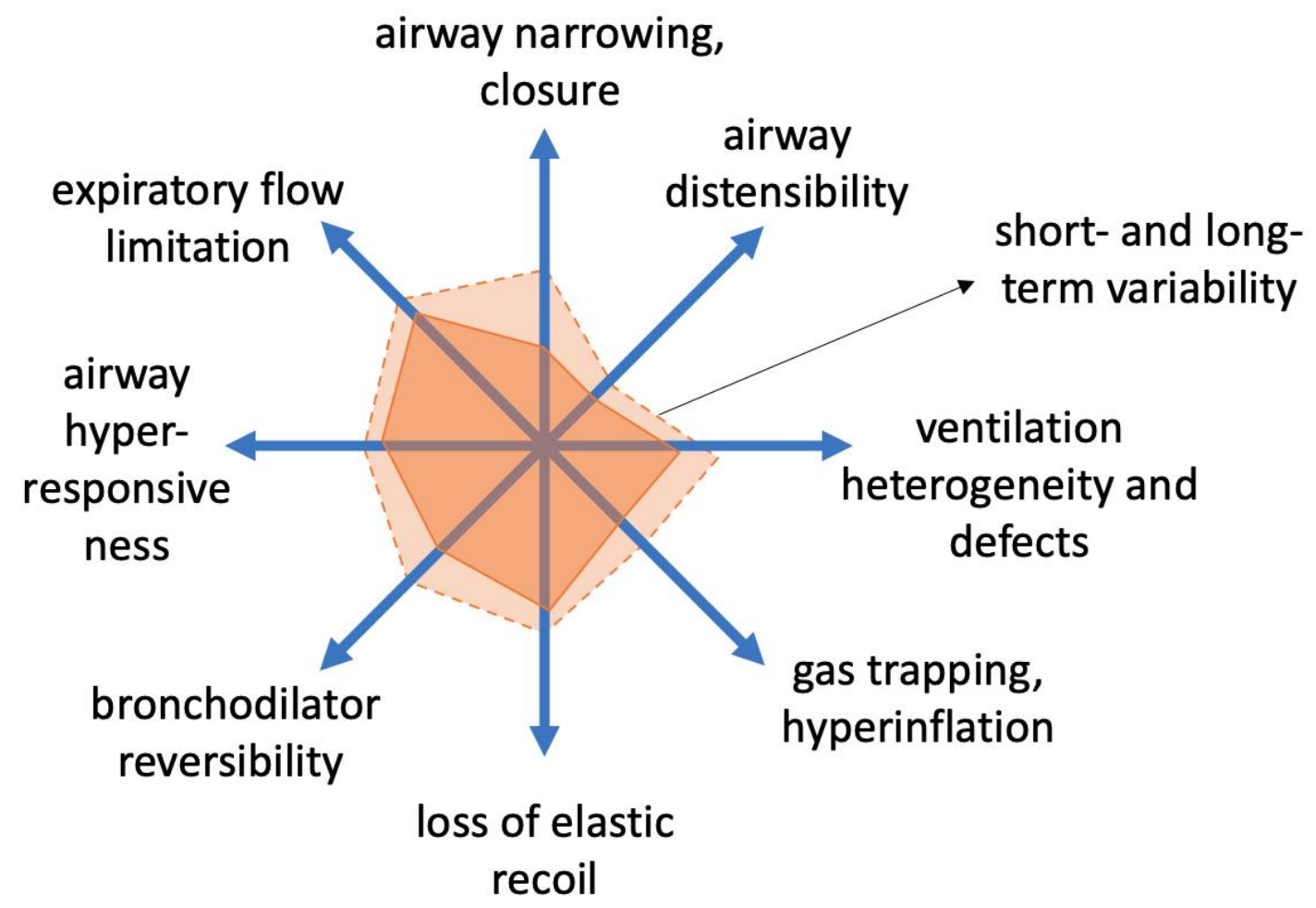

AIRWAYS DISEASE 